\title{
Urinary catheterization and female genital mutilation
}

\section{Abdulrahim A. Rouzi MB ChB}

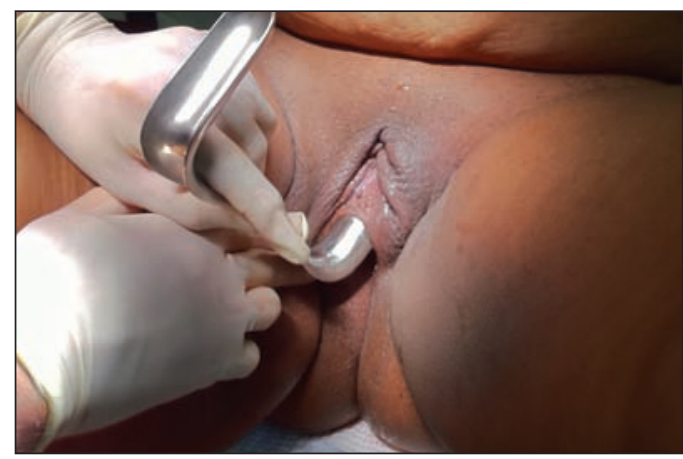

Figure 1: A lubricated Sim speculum is passed underneath the scar tissue in a 30-year-old pregnant woman with type III female genital mutilation.

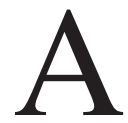
30-year-old African woman was admitted in labour at 37 weeks' gestation of her fifth pregnancy for emergency cesarean delivery. This was her first assessment for the current pregnancy at this hospital. She had a cesarean delivery with each of her previous pregnancies. On examination, she was found to have type III female genital mutilation that had been done during childhood.

She required urinary catheterization, which was performed by cleaning the genital area with antiseptic solution, inserting a lubricated sterile Sim speculum underneath the scar (Figure 1), pulling the speculum outward, and then lifting it in an upward direction to expose the urethra for cleaning with antiseptic solution and insertion of a Foley catheter under direct visualization (Figure 2). Routine cesarean delivery under general anesthesia was done without complications.

The World Health Organization estimates that between 100 and 140 million girls and women worldwide have experienced female genital mutilation, and around 3 million girls undergo some form of the procedure each year. ${ }^{1}$ Type III female genital mutilation (also known as infibulation) is defined by the World Health Organization as narrowing of the vaginal orifice with creation of a covering seal by cutting and appositioning the labia minora and/or the labia majora, with or without excision of the clitoris. ${ }^{1}$

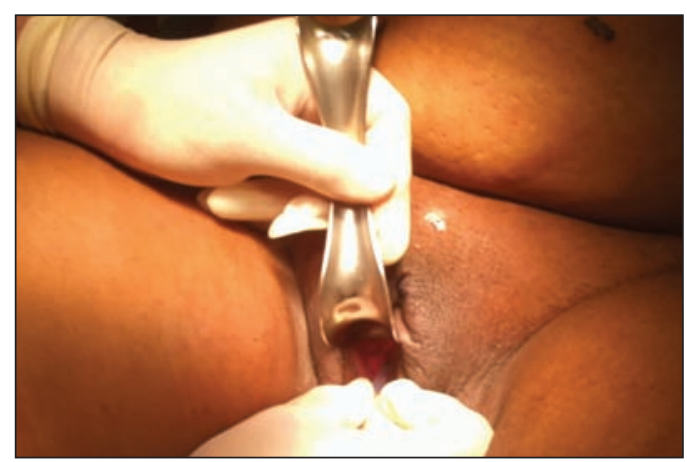

Figure 2: The Sim speculum is lifted upward to expose the urethra and allow insertion of the catheter.

The complications associated with this procedure are well documented. ${ }^{2}$

Inserting a catheter into the urinary bladder can be difficult in women who have had female genital mutilation, particularly type III, in which the scar tissue covers the urethral meatus and part of the vaginal introitus. In emergency situations in which urinary catheterization is required, ${ }^{3}$ the technique described above can be used to allow access for the urinary catheter (Appendix 1, available at www.cmaj.ca/lookup/suppl/doi: 10.1503/cmaj.111588/-/DC1). Defibulation (i.e., cutting the scar tissue) is another option. ${ }^{4}$

\section{References}

1. World Health Organization. Eliminating female genital mutilation: an interagency statement. Geneva (Switzerland): The Organization; 2008. Available: web.unfpa.org/upload/lib_pub _file/756_filename_fgm.pdf (accessed 2011 Oct. 24).

2. Royal College of Obstetricians and Gynaecologists. Female genital mutilation and its management. Green top guideline, no 53. London (UK): The College; 2009. Available: www.rcog.org.uk /files/rcog-corp/GreenTop53FemaleGenitalMutilation.pdf (accessed 2012 Feb. 13).

3. Rosenberg LB, Gibson K, Shuman JF. When cultures collide: female genital cutting and US obstetrics practice. Obstet Gynecol 2009;113:931-4

4. McCaffrey M, Jankowska A, Gordon H. Management of female genital mutilation: the Northwick Park Hospital experience. $\mathrm{Br} J$ Obstet Gynaecol 1995;102:787-90.
Competing interests: None declared.

Affiliation: From the Department of Obstetrics and Gynecology, King Abdulaziz University, Jeddah, Saudi Arabia

This article has been peer reviewed

Editor's note: Presented as a video presentation at the 67th Annual Meeting of the American Society of Reproductive Medicine, Oct. 15-19, 2011, Orlando, Fla.

Correspondence to: Abdulrahim Rouzi, aarouzi@gmail.com

CMAJ 2013. DOI:10.1503 /cmaj.111588 